\title{
THEME SECTION
}

\section{Space use by foraging Galápagos penguins during chick rearing}

\author{
Antje Steinfurth ${ }^{1,3, *}$, F. Hernan Vargas ${ }^{2,3,6}$, Rory P. Wilson ${ }^{4}$, Michael Spindler ${ }^{5}$, \\ David W. Macdonald ${ }^{2}$ \\ ${ }^{1}$ Research and Technology Centre (FTZ), University of Kiel, Hafentörn, 25761 Büsum, Germany \\ ${ }^{2}$ Department of Zoology , Wildlife Conservation Research Unit, University of Oxford, Tubney House, Abingdon Road, \\ Tubney, Oxfordshire OX13 5QL, UK \\ ${ }^{3}$ Charles Darwin Foundation, Isla Santa Cruz, Galápagos, Ecuador \\ ${ }^{4}$ School of Environment and Society University of Wales Swansea, Singleton Park, Swansea SA2 8PP, UK \\ ${ }^{5}$ Institute of Polar Biology, University of Kiel, Wischhofstr. 1-3, Building 12, 24148 Kiel, Germany \\ ${ }^{6}$ Present address: The Peregrine Fund/Fondo Peregrino Panamá, Apartado 0844-00230, Panamá City, Republic of Panama
}

\begin{abstract}
Between May 2004 and May 2005, we studied the horizontal and vertical movements of foraging Galápagos penguins Spheniscus mendiculus during their breeding season to examine space use at sea and to compare the volume of water exploited by this penguin to those of other penguin species. A total of 23 adult penguins (11 males and 12 females) brooding chicks were fitted with GPSdepth recorders at the 3 main nesting sites on south-western Isabela Island. Birds moved between 1.1 and $23.5 \mathrm{~km}$ (mean $=5.2 \pm 4.9 \mathrm{~km}$ ) from the nest, concentrating foraging in a strip of sea within $1.0 \mathrm{~km}$ of the shore. Foraging trips lasted a mean of $8.4 \pm 2.0 \mathrm{~h}$. Although the deepest dive was $52.1 \mathrm{~m}$, birds spent, on average, $90 \%$ of their time underwater at depths less than $6 \mathrm{~m}$. Both foraging ranges and dive depths were below those predicted from allometric regressions derived from other penguin species. Applying the maximum values for movement to calculate space use, the Galápagos penguin exploits a maximum volume of water of $<1.4 \mathrm{~km}^{3}$, which is almost 90 times less than that predicted for its mass, and thus utilises only a small portion of the total potentially available upwelling area within the Galápagos Archipelago.
\end{abstract}

KEY WORDS: Galápagos penguin · Spheniscus mendiculus · Endangered species · Conservation · Foraging range Resale or republication not permitted without written consent of the publisher

\section{INTRODUCTION}

The Galápagos penguin Spheniscus mendiculus, the most northerly breeding penguin species and endemic to the Galápagos Archipelago, is classified as 'endangered' by the IUCN, the World Conservation Union (BirdLife International 2000), with a total population of around 2000 individuals (Jiménez-Uzcátegui et al. 2006).

Total populations of the 3 congeners (African penguin Spheniscus demersus, Magellanic penguin S. magellanicus and Humboldt penguin $S$. humboldti) have historically numbered millions of individuals (Williams 1995), whereas studies since 1970 indicate that the Galápagos penguin population has always been consistently low (Vargas et al. 2005). All Spheniscus penguins are specialised to feed on pelagic school fish such as anchovies Engraulis spp. and sardines Sardinops spp. (for review see Williams 1995, Wilson \& Wilson 1995) and, due to their limited foraging range as a consequence of their flightlessness (Wilson 1985), exploit primarily highly productive environments such as upwellings (Williams 1995) and continental shelves (Wilson et al. 1995).

Accordingly, the Galápagos penguin distribution coincides with the main upwelling areas of the archi- 
pelago (Boersma 1978). Although this upwelling is not as extensive as either the Benguela or Humboldt system which feed African and Humboldt penguins, respectively, or the Patagonian Shelf, over which Magellanic penguins forage (Boersma et al. 2007), approximately $95 \%$ of the penguin's population is found along the western coast of Isabela and around Fernandina Island (Vargas et al. 2007), which are the primary areas of upwelling caused by the Equatorial Undercurrent, also known as the Cromwell Current (Palacios 2004). However, distributional records (Mills 1998, 2000, Jiménez-Uzcátegui et al. 2006) suggest that this species may not use the whole extent of the upwelling habitat potentially available to it.

We examined the foraging range used by Galápagos penguins by equipping birds with Global Positioning System and depth (GPS-depth) loggers (earth\&OCEAN Technologies) during their breeding period in 2004 and 2005. We measured the Galápagos penguin's horizontal and vertical movement at sea to assess whether their foraging ranges and volumes of sea exploited differ from those of other species.

\section{MATERIALS AND METHODS}

Study site. The study was conducted between 8 May 2004 and 27 May 2005, at the 3 principal nesting sites of the Galápagos penguin on Isabela Island: (1) Caleta Iguana $\left(0.98^{\circ} \mathrm{S}, 91.45^{\circ} \mathrm{W}\right)$, (2) Playa de los Perros $\left(0.79^{\circ} \mathrm{S}, 91.43^{\circ} \mathrm{W}\right)$ and (3) Las Marielas $\left(0.60^{\circ} \mathrm{S}\right.$, $91.09^{\circ}$ W) (Fig. 1) (A. Steinfurth \& F. H. Vargas unpubl. data).

Deployment of devices. Both the methodology and bird handling followed Wilson \& $\mathrm{Cu}$ lik (1992) and Bannasch et al. (1994) and complied with the laws and regulations of Ecuador and the guidance of the UK Animals (Scientific Procedures) Act 1986. Adult penguins brooding chicks were captured using a lasso, a foot-hook or by hand, and were weighed to the nearest $100 \mathrm{~g}$ using a $5 \mathrm{~kg}$ spring balance (Pesola ${ }^{\circledR}$ ). In addition to body mass, palpation of pectoral muscles was used to ensure that captured birds were in good condition. Measurements of bill length, depth, and width, as well as flipper length were taken with callipers to the nearest $0.1 \mathrm{~mm}$ to determine the sex of the individual (Boersma 1977). Blood samples were taken to confirm gender by genetic sexing in the laboratory (Travis et al. 2006). All birds were individually marked with a PIT- (Passive Integrated Transponder) tag in their left leg as part of a separate study (F. H. Vargas unpubl. data).
After capture, birds were equipped with the GPS loggers placed midline on the lower back, following Bannasch et al. (1994) using overlapping layers of black waterproof tape $(10 \mathrm{~mm}$ wide strip Tesa-Tape Nr. 4651, Beiersdorf) which matched the birds' plumage in colour and did not compromise feather structure (Wilson \& Wilson 1989, Wilson et al. 1990). The complete procedure, from capture to release, took less than $20 \mathrm{~min}$. The GPSdepth loggers consisted of electronics in a streamlined aramide fibre/epoxy-composite housing with polyoxymethylene cap, and had maximum dimensions of $100 \times$ $48 \times 24 \mathrm{~mm}$ (75 g) (Ryan et al. 2004, Petersen et al. 2006). Geographical position (using the World Geodetic System, WGS, standard) and pressure (0 to 10 bar with 12 bit resolution; absolute measurement uncertainty \pm 0.03 bar) were nominally recorded once per second although positional estimates were only actually recorded when the birds were long enough at the surface for a fix to be obtained from the satellite data. Using this set-up, data could be collected over a period of up to $12 \mathrm{~h}$. In most cases, device deployment took place in the late afternoon, when both parents were attending the chick/s. The GPS-depth units were programmed to switch on automatically at $05: 00 \mathrm{~h}$ the following morning, before birds headed out to sea. Equipped birds were recaptured after 1 to $3 \mathrm{~d}$; removal of the equipment took about $5 \mathrm{~min}$. The recorded data were downloaded onto a field computer for subsequent analysis.

Data analysis and statistics. Pressure data were analysed using MT-Dive software (Jensen Software System) to derive the total time spent per unit depth for each individual bird histogram with time summed over $0.5 \mathrm{~m}$

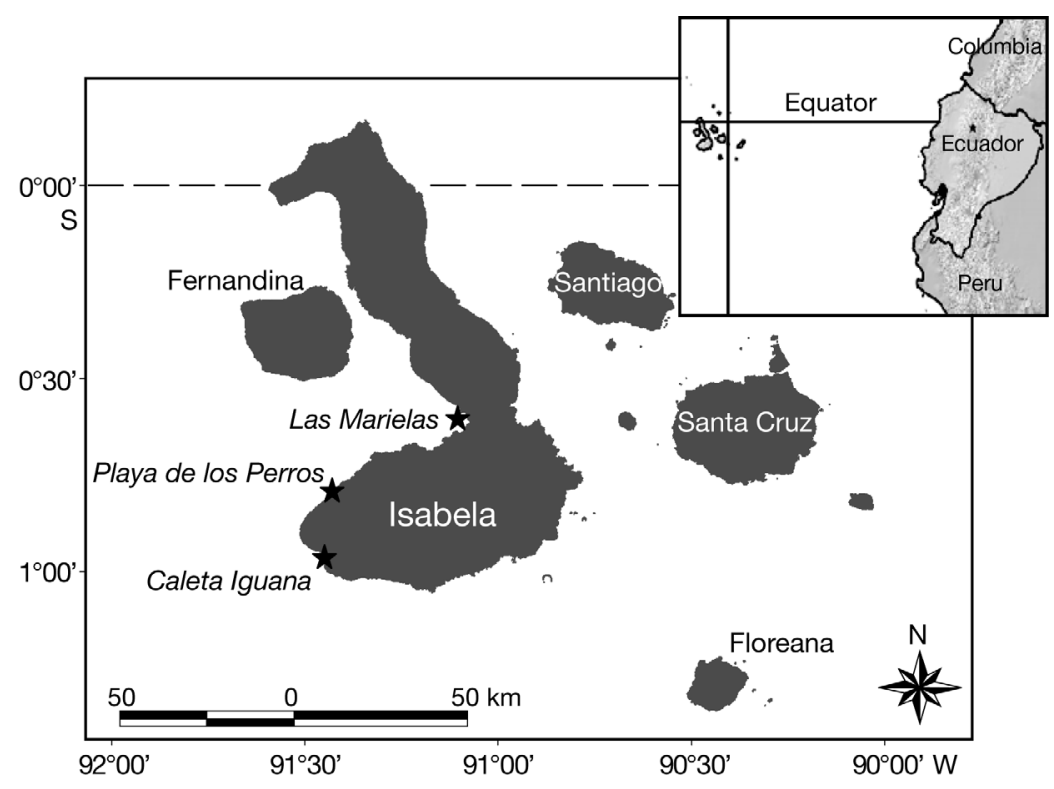

Fig. 1. Map of the Galápagos Islands showing the 3 main breeeding sites of the Galápagos penguin ( $\star$ : Caleta Iguana, Playa de los Perros and Las Marielas) where penguins were equipped with GPS-depth loggers 
intervals. The time elapsed between leaving and returning to the nest was used to define foraging trip length.

GPS data were analysed in Arcview. Distances between positional fixes and shoreline and distances moved from the nest were calculated with ArcView 3.2, extension Geoprocessing. Distances were measured in a straight line (and not following the coastline), and therefore represent minimum values. A base map of the Galápagos Islands (1996, Datum WGS 84, scale 1:100 000) was used to examine foraging ranges and distances from shore. Due to errors in the base map of the Galápagos Islands (of about $50 \mathrm{~m}$ ) and the GPS-depth units (between \pm 3 and $\pm 19 \mathrm{~m}$, see GPS-depth manual, earth\&OCEAN Technologies, and also Ryan et al. 2004), the map of Isabela Island was manipulated in ArcView and shifted approximately $200 \mathrm{~m}$ eastward. This manipulation was validated by our foraging movement GPS data (indicating that birds were diving at sea), by GPS tracks taken by one of the authors walking along the high tide level, and by fixes taken with a hand-held Garmin 12CX GPS receiver to locate nest sites. The statistical analysis was carried out using a linear mixed effect model (Software R 2.4.1 lme4) (Pinheiro \& Bates 2000).

\section{RESULTS}

\section{Logger deployment}

Twenty-three birds (11 males and 12 females) were successfully fitted with GPS-depth loggers while brooding one (12 birds) or two (11 birds) small to medium chicks. Of these, 16 individuals were studied at Caleta Iguana, 6 at Playa de los Perros and 1 at Las Marielas. All the devices were recovered, no nest was deserted and no other adverse effects were apparent from individual birds. Of all the device-equipped birds, mean \pm SD body mass was significantly higher in males $(2.1 \pm 0.2 \mathrm{~kg})$ than females $(1.8 \pm 0.3 \mathrm{~kg})(\mathrm{p}=0.0083)$.

Of the 23 equipped birds, 21 yielded useful GPS data and are included in the present analysis. Reasons for unsuccessful deployments involved birds not leaving their nesting site (1 bird) and no data recording due to errors in programming (1 bird). Only 12 data sets provided information on the full foraging trip length and were thus used in the dive parameter analysis. In the remaining 8 cases, the battery had run out before the foraging trip was completed.

\section{Movements at sea}

The mean $( \pm \mathrm{SD})$ maximum distance travelled away from the nest during foraging, irrespective of the direction, was $5.2 \pm 4.9 \mathrm{~km}$ (range 1.1 to $23.5, \mathrm{n}=$ 21), there being no significant difference between males (mean $6.4 \pm 6.5$, range 1.1 to $23.5 \mathrm{~km}, \mathrm{n}=11$ ) and females (mean $3.9 \pm 1.7$, range 1.6 to $6.6 \mathrm{~km}, \mathrm{n}=10)(\mathrm{p}$ $>0.05$ ). One bird (PP-19) moved at least $23.5 \mathrm{~km}$ from the nest in $1 \mathrm{~d}$, nearly 5 times the mean maximum distance. If this outlier is removed, the mean maximum distance away from the nest was $4.3 \pm 2.7 \mathrm{~km}$, with location-specific mean distances of $4.8 \pm 2.7 \mathrm{~km}$ (Caleta Iguana, range $=1.8$ to 11.5 ), $2.5 \pm 1.9 \mathrm{~km}$ (Playa de los Perros, range 1.0 to 5.2 ) and $3.1 \mathrm{~km}$ (Las Marielas; only 1 bird sampled) (Fig. 2a). Furthermore, penguin movement at Caleta Iguana and Playa de los Perros was highly biased towards travelling parallel with the coast (Fig. 3b,c). The single device-equipped bird at Las Marielas headed away from the small islet towards the inshore waters of Isabela Island to then travel close to the coast of the island (Fig. 3a). Due to the small sample size this single bird was excluded from all statistical analyses. The maximum recorded distance from the coast was $0.9 \mathrm{~km}$ ( $\mathrm{n}=20$ birds) (Fig. $2 \mathrm{~b}$ ), indicating that foraging occurred within the $50 \mathrm{~m}$ depth zone off the coast. Although there were no inter-
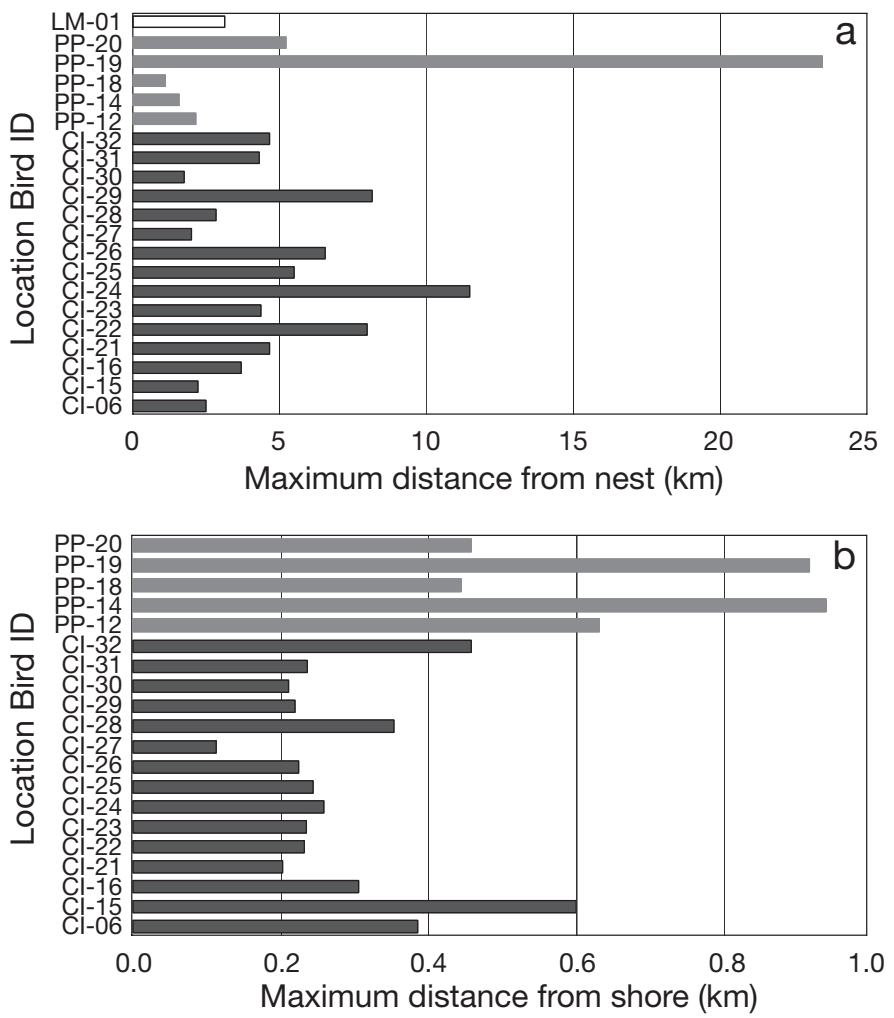

Fig. 2. Spheniscus mendiculus. (a) Maximum distances moved by penguins (measured in a straight line) from nests at Caleta Iguana ( $\mathrm{CI}_{\text {; }}$ dark grey bars), Playa de los Perros (PP; light grey bars) and Las Marielas (LM; white bar). Note that bird PP-19 travelled nearly 5 times farther than the overall mean. (b) Maximum distance moved from shore by 20 penguins at $\mathrm{CI}$ and $\mathrm{PP}$ 



Fig. 3. Spheniscus mendiculus. Examples of movements of foraging penguins (round-trips) at (a) Las Marielas (1 bird), (b) Playa de los Perros (2 birds) and (c) Caleta Iguana ( 2 birds). Bathymetry is also shown
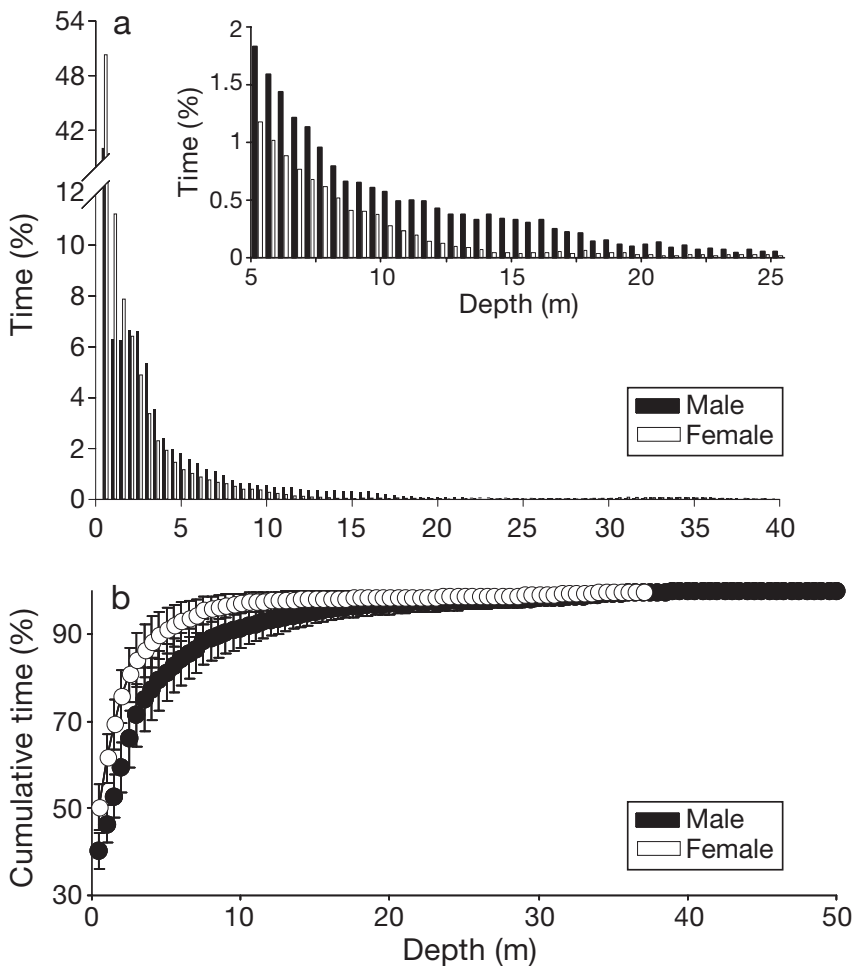

Fig. 4. Spheniscus mendiculus. (a) Mean percentage time spent per metre water depth by male and female Galápagos penguins. Insert shows relationships for 5 to $25 \mathrm{~m}$ in greater detail. (b) Mean $( \pm \mathrm{SE})$ cumulative time spent with increasing water depth for male and female Galápagos penguins

sex differences, site-specific differences were apparent $(p<0.0001)$, with birds at Playa de los Perros foraging further offshore than at Caleta Iguana. Also, no significant differences in movement behaviour occurred for adults raising 1 chick compared to 2 chicks ( $p$ > $0.05)$.

\section{Diving behaviour}

All of the successful device deployments delivered data from 1 foraging trip. Foraging trips lasted a mean $( \pm \mathrm{SD})$ of $8.4 \pm 2.0 \mathrm{~h}(\mathrm{n}=12$ birds $)$, with penguins leaving the nest to go to the sea between 05:11 and 05:48 h and returning between 11:04 and 17:00 h. Penguins foraged predominantly in surface waters, spending a decreasing amount of time with increasing depth (Fig. 4a). The maximum dive depth recorded for any individual was $52.1 \mathrm{~m}$ by a female foraging from Caleta Iguana although overall mean dive depth was $3.0 \pm 2.2 \mathrm{~m}$. Mean limits for $90 \%$ of time spent diving occurred at $8.5 \mathrm{~m}$ depth for males and $4 \mathrm{~m}$ for females (Fig. 4b). There were no significant differences in foraging trip duration between sexes or sites or number of brooding chicks $(n=12, p>0.05)$. 


\section{DISCUSSION}

\section{Device effects and potential biases associated with GPS tracking instruments}

The attachment of external devices to free-living animals is known to affect behaviour (Wilson et al. 1986, 1990, Culik \& Wilson 1991, Bannasch et al. 1994, Taylor et al. 2001), so particular attention was paid to bird handling and the precise placement of our GPSdepth units. The GPS devices used in our study were relatively large, although still just below the threshold value of $5 \%$ body mass (Wilson \& Culik 1992). Nevertheless, increased drag associated with the device deployment is inevitable, tending to reduce penguin swim speed (Wilson et al. 1986), dive performance (Wilson et al. 1991, Ropert-Coudert et al. 2007) and likely food intake (Wilson et al. 2004), and cognisance needs to be taken of this. Despite this, and although no control study was carried out, we could detect no deleterious effects on either adult well-being or chickrearing performance during the study.

Several potential biases might also have occurred in the interpretation of GPS tracking data. Although the device was programmed to record positions continuously, the number of locations acquired varies according to diving behaviour because positional fixes can only be obtained when the birds are at the water surface long enough to receive the relevant information from the satellites (Ryan et al. 2004). Thus, there were short periods when no positional data could be derived, which could potentially affect both estimates of trip range and distance from the coast.

For the pupose of this study, no differentiation was made between travel and foraging dives during penguin excursions to sea.

\section{Foraging ranges, depths and volumes of water exploited}

Greater foraging ranges are tenable in larger species for 2 reasons: (1) Chicks can be provisioned for extended periods by larger brooding adults because they have comparatively larger stomachs to store food, a process that is facilitated by food conservation mechanisms in the gut (Thouzeau et al. 2003). This is advantageous with respect to foraging range because where a single adult can provision the brood for long periods this allows the partner time to range farther since foraging duration correlates strongly with foraging range (e.g. Petersen et al. 2006). (2) Both larger chicks and adults can fast for longer periods (Groscolas \& Robin 2001), so that brooding adults and the chicks from larger species cope better with extended absences of the parent or partner.
Accordingly, published data for 13 species of penguin (brooding small to medium chicks) show that there is a general trend for foraging ranges to increase with body mass as shown by:

$$
\text { Range }=24.73 \mathrm{e}^{0.1395 \text { Mass }}\left(\mathrm{r}^{2}=0.76, F=120.3, \mathrm{p}<0.05\right)
$$

According to this regression, the Galápagos penguin, with a body mass of ca. $2 \mathrm{~kg}$, is predicted to have a foraging range of $30.7 \mathrm{~km}$. Our derived maximum range of $23.6 \mathrm{~km}$ is markedly lower than this and even lower than that of the little penguin Eudyptula minor, a species which has half the mass of the Galápagos penguin and which may range over $30 \mathrm{~km}$ during chick provisioning (e.g. Norman 1992, Collins et al. 1999).

In addition, the data presented for all species other than the Galápagos penguin refer to general foraging range, which usually entails movement directly away from the foraging site and away from the coast (e.g. Culik \& Luna-Jorquera 1997, Barlow \& Croxall 2002, Ainley et al. 2004, Petersen et al. 2006). The observation that none of the GPS-depth recorder-equipped Galápagos penguins ranged farther than $1.0 \mathrm{~km}$ from the nearest coast indicates that the actual area of sea they utilise is even smaller than their range would suggest. This can be illustrated by a simple model that assumes that all other penguin species forage over a semi-circle. We consider that a semi-circle is a reasonable general approximation (cf. Wilson et al. 1988, 1995, Wilson 1995), although the arc over which different species may forage varies between as little as $35^{\circ}$ (Barlow \& Croxall 2002) and virtually a full circle (e.g. Jouventin et al. 1994 for King penguins Aptenodytes patagonicus). Based on this general assumption, the area that can be exploited translates into $\left(\pi r^{2}\right) / 2$, where $r$ is the foraging range, so that the regression of foraging range versus mass can be altered into foraging area versus mass via:

$$
\text { Area }=\left[\pi\left(24.73 \mathrm{e}^{0.1395}\right)^{2}\right] / 2
$$

The limits on this lie between Area = $\left[\pi\left(24.73 \mathrm{e}^{0.1395}\right)^{2}\right] /(35 / 360)$ and Area $=\left[\pi\left(24.73 \mathrm{e}^{0.1395}\right)^{2}\right]$ if the movement arcs taken for Macaroni Eudyptes chrysolophus and King penguins are taken as minima and maxima, respectively. By contrast, the sea area available to the Galápagos penguin is only effectively given by the distance from the coast multiplied by twice the range (since the foraging bird may normally move in one of 2 directions when leaving the colony). Using $95 \%$ confidence limits on the data gleaned from the GPS data, these only amounted to about $24 \mathrm{~km}^{2}$, markedly smaller than the postulated mass-specific area used by penguins, and even smaller than that of Macaroni penguins with their highly restricted foraging arc.

Putative foraging areas exploited by breeding penguins are modulated by the depths that the birds can 
exploit. In this regard, regressions of absolute maximum depth versus body mass in Wilson (1995) predict that the Galápagos penguin should be able to dive to a maximum of $85 \mathrm{~m}$, which substantially exceeds the recorded maxima of $52.1 \mathrm{~m}$. However, such measures are of limited value since they are highly dependent on sample size (since the chances of an individual executing an exceptional dive increase with sample size) and, in any case, tend to represent physiological maxima rather than anything of ecological relevance.

If we assume that the Galápagos penguin dive data are typical, it is possible to determine the volume of water that can be exploited by this bird by simply multiplying the maximum recorded depth $(52.1 \mathrm{~m}$, itself an outlier compared to other values) by the exploitable area $\left(24 \mathrm{~km}^{2}\right)$. Similar calculations using other penguin species demonstrate the huge discrepancy that may exist between the Galápagos and the other species in the volume of water searched by breeding birds (Fig. 5). Indeed, even if the volume of water available to penguins is corrected to become mass-specific, the volume of water exploited by the Galápagos penguin is about 1000 times less than that expolited by other penguin species.

The primary factor in reducing the potential volume comes from the coast-hugging behaviour of the species. There are a number of possible explanations for this.

Firstly, their primary prey may be located inshore. In fact, to date, there are few data on the feeding habits of the Galápagos penguin. Both Boersma (1974) and Vargas et al. (2006) report that it feeds on mullet (Mugilidae), and Mills (1998) notes that the species is occasionally seen feeding with aggregations of seabirds, exploiting what are assumed to be sardines Sardinops sagax. Vargas et al. (2006) also noted that the Galápagos penguin feeds on piquitangas Lile stolifera around Fernandina Island. Finally, 9 stomach samples of nonbreeding adults collected during 2005 using a wateroffloading method (Wilson 1984) revealed that these individuals were feeding predominately on larvae or juvenile anchovies Engraulis sp. (and fish most likely stemming from sardines and/or mullet Mugil spp., mean size $26 \mathrm{~mm}$; A. Steinfurth unpubl. data). Both sardine and anchovy are typical of upwelling systems, and their larvae and juvenile phases inhabit the surface inshore waters but migrate off-shore when adult (www.fishbase.org). Similarly, the local mullet are schooling fish that inhabit sand, mud and rock bottoms of shallow waters near the coast (www.fishbase.org).

Another possible explanation relates to predation. It has been suggested that the paucity of non-volant pursuit divers in the tropics is related to increased predation by sharks (Au \& Pitman 1986, Schreiber \& Burger 2001, Weimerskirch et al. 2005). Fifteen species of shark have been recorded from the Galápagos Archipelago (Humann 1993), so Galápagos penguin
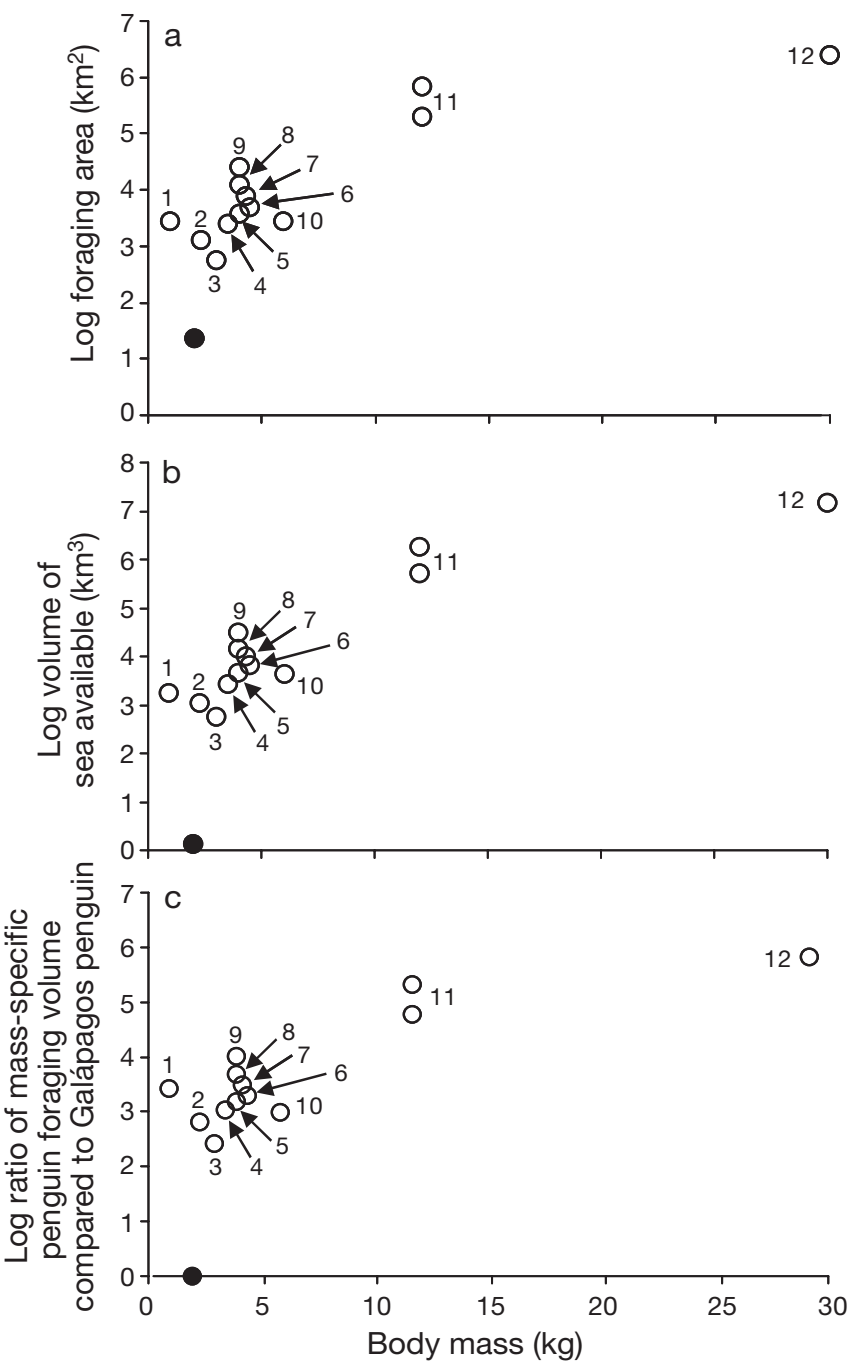

Fig. 5. (a) Relationship between the putative foraging area available to different penguin species hunting for small or medium chicks as a function of body mass (for calculations see 'Discussion'). @: Galápagos penguin; other penguin species (O): 1, little penguin Eudyptula minor; 2, rockhopper penguin Eudyptes chrysocome; 3, African penguin Spheniscus demersus; 4, chinstrap penguin Pygoscelis antarctica; 5, Humboldt penguin Spheniscus humboldti; 6, Adelie penguin Pygoscelis adeliae; 7, royal penguin Eudyptes schlegeli; 8, macaroni penguin Eudyptes chrysolophus; 9, Magellanic penguin Spheniscus magellanicus; 10, gentoo penguin $P Y-$ goscelis papua; 11, king penguin Aptenodytes patagonicus; 12, emperor penguin Aptenodytes forsteri. Two values are shown for the king penguin since the literature indicates considerable variation for this species (Charrassin \& Bost 2001). (b) Relationship between the foraging volume available to different penguin species as a function of body mass (for calculations see 'Discussion'). Maximum depth data derived from references given in (1) Montague (1985), (2) Tremblay et al. (1997), (3) Wilson (1985), (4) Mori (1997), (5) Taylor et al. (2004), (6) Arai et al. (2000), (7) Hull (2000), (8) Croxall et al. (1993), (9) Walker \& Boersma (2003), (10) Robinson \& Hindell (1996), (11) Pütz \& Cherel (2005), (12) Kooyman \& Kooyman (1995). (c) Ratio between the mass-specific volume of sea available for foraging for different penguin species and that available to the Galápagos penguin 
foraging ecology could be influenced by predator avoidance (Heithaus \& Frid 2003).

These first data on the space use of the Galápagos penguin, which were taken over an extensive period of one year, suggest that the foraging habitat used by the penguins is only a small fraction of the upwelling zone and, thus, the potential marine habitat available to them. It is unclear why the foraging areas and volumes of this species are so much smaller than those of other penguin species at a similar stage of breeding. If food were abundant at the time the study was conducted, there may have been no need for the population to forage farther afield than it did, even if the birds were capable of doing so. However, the extremely aberrant coast-hugging behaviour of the Galápagos penguin, which is shown by no other penguin species, indicates that some factor other than food limits the range. Where factors other than food distribution act to compromise potential foraging volumes, we would expect overall food availability to be similarly compromised and, indeed, this state of affairs alone might explain why Galápagos penguins are the only member of their genus to occur exclusively in small colonies.

Future studies need to examine the area and depth use of Galápagos penguins during the non-breeding season in order to be able to explain observed patterns more definitively. Certainly, an understanding of what limits area use by foraging Galápagos penguins has important implications for estimates of the distribution at sea and of habitat used by Galápagos penguins as well as for assessments of whether expanding anthropogenic activities, including commercial fisheries, may be potentially harmful to penguin populations.

Future work should address the precise conditions that determine penguin foraging success and nesting requirements, since the birds can clearly only breed in areas close to appropriate marine conditions. The likelihood of both conditions occurring together may already be reduced but further man-induced deterioration in either of these could prove critical to the survival of this species.

Acknowledgements. We are grateful to the Charles Darwin Foundation (Contribution no. 1045) and the Galápagos National Park Service (GNPS) for logistic support. The GNPS granted permission to carry out the work and provided invaluable assistance in the field. We also thank Santiago Torres, Fransciso Cruz, Susana Cardenas, Carlos Carrion, Carlos Vinueza, Juan Carlos Valarezo, Günter Steinfurth and the crews of the 'Golondrina I' and 'Queen Mabel' for their invaluable help and hard work in the field. Many thanks to Gerrit Peters from earth\&OCEAN technologies for his assistance in managing devices and associated software. Furthermore, we are grateful to Stephen Barlow, Stefan Garthe and Sven Adler for statistical advice and Wacho Llerena and Bettina Mendel for their help on the GPS data analysis. This study was funded by the Darwin Initiative for the Conserva- tion of Biodiversity, the German Academic Exchange Service, and Boehringer Ingelheim Fonds. Further support was given by Swarovsky \& Co., the Whitley Lang Foundation (Rufford PhD Grant), the Swiss Friends of Galápagos, the Galápagos Conservation Trust, SeaWorld, Beiersdorf, SIGG, Swiss Victorinox, Pesola, Pelican Case and Aquapac.

\section{LITERATURE CITED}

Ainley DG, Ribic CA, Ballard G, Heath S and 5 others (2004) Geographic structure of Adelie penguin populations: overlap in colony-specific foraging areas. Ecol Monogr 74: 159-178

Arai N, Kuroki M, Sakamoto W, Naito Y (2000) Analysis of diving behavior of Adelie penguin using acceleration data logger in the JARE 39. Polar Biosci 13:95-100

Au DWK, Pitman RL (1986) Seabird interactions with dolphins and tuna in the Eastern Tropical Pacific. Condor 88: 304-317

Bannasch R, Wilson RP, Culik BM (1994) Hydrodynamic aspects of design and attachment of a back-mounted device in penguins. J Exp Biol 194:83-96

Barlow KE, Croxall JP (2002) Seasonal and interannual variation in foraging range and habitat of macaroni penguins Eudyptes chrysolophus at South Georgia. Mar Ecol Prog Ser 232:291-304

BirdLife International (2000) Threatened birds of the world. Lynx Edicion and BirdLife International, Barcelona and Cambridge

Boersma PD (1974) The Galápagos penguin: adaptation for life in an unpredictable environment. $\mathrm{PhD}$ dissertation, Ohio State University, Columbus, $\mathrm{OH}$

Boersma PD (1977) An ecological and behavioural study of the Galápagos penguin. Living Bird 15:43-93

Boersma PD (1978) Breeding patterns of Galápagos penguins as an indicator of oceanographic conditions. Science 200: 1481-1483

Boersma PD, Rebstock GA, Stokes DL, Majluf P (2007) Oceans apart: conservation models for two temperate penguin species shaped by the marine environment. Mar Ecol Prog Ser 335:217-225

Charrassin JB, Bost CA (2001) Utilisation of the oceanic habitat by king penguins over the anual cycle. Mar Ecol Prog Ser 221:285-297

Collins M, Cullen JM, Dann P (1999) Seasonal and annual foraging movements of little penguins from Phillip Island, Victoria. Wildl Res 26:705-721

Croxall JP, Briggs D, Kato A, Naito Y, Watanuki Y, Williams T (1993) Diving pattern and performance in the macaroni penguins Eudyptes chysolophus. J Zool (Lond) 230:31-47

Culik BM, Luna-Jorquera G (1997) Satellite tracking of Humboldt penguins (Spheniscus humboldti) in northern Chile. Mar Biol 128:547-556

Culik BM, Wilson RP (1991) Swimming energetics and performance of instrumented Adelie penguins (Pygoscelis adeliae). J Exp Biol 158:355-368

Groscolas R, Robin JP (2001) Long term fasting and re-feeding in penguins. Comp Biochem Physiol A 128:645-655

Heithaus MR, Frid A (2003) Optimal diving under the risk of predation. J Theor Biol 223:79-92

Houvenaghel GT (1984) Oceanographic setting of the Galápagos Islands. In: Perry RR (ed) Key environments - Galápagos. Pergamon Press, Oxford, p 43-54

Hull CL (2000) Comparative diving behaviour and segregation of the marine habitat by breeding Royal Penguins, Eudyptes schlegeli, and eastern Rockhopper Penguins, 
Eudyptes chrysocome filholi, at Macquarie Island. Can J Zool 78:333-345

Humann P (1993) Reef fish identification: Galápagos. New World, Jacksonville, FL

Jiménez-Uzcátegui G, Vargas FH, Larrea C, Milstead B, Llerena W (2006) Galápagos penguin and flightless cormorant survey. Tech Rep to the Charles Darwin Foundation and the Galápagos National Park Service. Charles Darwin Foundation, Galápagos, Puerto Ayora

Jouventin P, Capdeville D, Cuenot-Chaillet R, Boiteau C (1994) Exploitation of pelagic resources by a non-flying seabird: satellite tracking of the king penguin throughout the breeding cycle. Mar Ecol Prog Ser 106:11-19

Kooyman GL, Kooyman T (1995) Diving behavior of Emperor penguins nurturing chicks at Coulman Island, Antarctica. Condor 97:536-549

Mills KL (1998) Multispecies seabird feeding flocks in the Galápagos Islands. Condor 100:277-285

Mills KL (2000) Diving behaviour of two Galápagos penguins Spheniscus mendiculus. Mar Ornithol 28:75-79

Montague T (1985) A maximum dive recorder for little penguins. Emu 85:264-267

Mori Y (1997) Dive bout organization in the Chinstrap penguin at Seal Island, Antarctica. J Ethol 15:9-15

Norman FI (1992) Distribution and abundance of seabirds off Phillip Island and within Port Phillip Bay, Victoria, 1986-1988. Emu 91:377-394

Palacios DM (2004) Seasonal patterns of sea-surface temperature and ocean color around the Galápagos: regional and local influences. Deep-Sea Res II 51:43-57

Petersen SL, Ryan PG, Gremillet D (2006) Is food availability limiting African penguins Spheniscus demersus at Boulders? A comparison of foraging effort at mainland and island colonies. Ibis 148:14-26

Pinheiro JC, Bates DM (2000) Mixed-Effects Models in S and S-Plus. Statistics and computing. Springer, New York

Pütz K, Cherel Y (2005) The diving behaviour of brooding King penguins (Aptenodytes patagonicus) from the Falkland Islands: variation in dive profiles and synchronous underwater swimming provide new insights into their foraging strategies. Mar Biol 147:281-290

Robinson SA, Hindell MA (1996) Foraging ecology of Gentoo penguins Pygoscelis papua at Macquarie Island during the period of chick care. Ibis 138:722-731

Ropert-Coudert Y, Knott N, Chiaradia A, Kato A (2007) How do different data logger sizes and attachment positions affect the diving behaviour of Little penguins? Deep-Sea Res II 54:415-423

Ryan PG, Petersen SL, Peters G, Grémillet D (2004) GPS tracking a marine predator: the effects of precision, resolution and sampling rate on foraging tracks of African penguins. Mar Biol 145:215-223

Schreiber EA, Burger J (2001) Biology of marine birds. CRC Press, Boca Raton, FL

Taylor SS, Boness DJ, Majluf P (2001) Foraging trip duration increases for Humboldt penguins tagged with recording devices. J Avian Biol 32:369-372

Taylor SS, Leonard ML, Boness DJ, Majluf P (2004) Humboldt penguins Spheniscus humboldti change their foraging behaviour following breeding failure. Mar Ornithol 32: 63-67

Thouzeau C, Le Maho Y, Froget G, Sabatier L, Le Bohec C, Hoffmann JA, Bulet P (2003) Spheniscins, avian betadefensins in preserved stomach contents of the King penguin, Aptenodytes patagonicus. J Biol Chem 278: 51053-51058
Travis EK, Vargas FH, Merkel J, Merkel J, Gottdenker N, Miller RE, Parker PG (2006) Hematology, serum chemistry, and serology of Galápagos penguins (Spheniscus mendiculus) in the Galápagos Islands, Ecuador. J Wildl Dis 42(3): 6

Tremblay Y, Guinard E, Cherel Y (1997) Maximum diving depths of northern Rockhopper penguins (Eudyptes chrysocome moseleyi) at Amsterdam Island. Polar Biol 17: 119-122

Vargas H, Lougheed C, Snell H (2005) Population size and trends of the Galápagos penguin Spheniscus mendiculus. Ibis 147:367-374

Vargas FH, Harrison S, Rea S, Macdonald DW (2006) Biological effects of El Niño on the Galápagos penguin. Biol Conserv 127:107-114

Vargas FH, Lacy RC, Johnson PJ, Steinfurth A, Crawford RJM, Boersma PD, Macdonald DW (2007) Modeling the effect of El Niño on the persistence of small populations: the Galápagos penguin as a case study. Biol Conserv 137:138-148

Walker BG, Boersma PD (2003) Diving behavior of Magellanic penguins (Spheniscus magellanicus) at Punta Tombo, Argentina. Can J Zool 81:1471-1483

Weimerskirch H, Le Corre M, Ropert-Coudert Y, Kato A, Marsac F (2005) The three-dimensional flight of redfooted boobies: adaptations to foraging in a tropical environment? Proc R Soc Lond B 272:53-61

Williams TD (1995) The penguins. Oxford University Press, Oxford

Wilson RP (1984) An improved stomach pump for penguins and other seabirds. J Field Ornithol 55:109-112

Wilson RP (1985) The Jackass Penguin (Spheniscus demersus) as a pelagic predator. Mar Ecol Prog Ser 25:219-227

Wilson RP (1995) The foraging ecology of penguins. In: Williams TD (ed) Penguins. Oxford University Press, Oxford, p 81-106

Wilson RP, Culik BM (1992) Packages on penguins and device-induced data. In: Priede I, Swift $\mathrm{S}$ (eds) Wildlife telemetry. Ellis Horwood, Chichester, p 573-580

Wilson RP, Wilson MPTJ (1989) Tape: a package-attachment technique for penguins. Wildl Soc Bull 17:77-79

Wilson RP, Wilson MP (1995) The foraging behaviour of the African penguin. In: Dann P, Norman I, Reilly P (eds) The penguins: ecology and management. Surrey Beatty \& Sons, Sydney, p 244-265

Wilson RP, Grant WS, Duffy DC (1986) Recording devices on free-ranging marine animals: does measurement affect foraging performance? Ecology 67:1091-1093

Wilson RP, Wilson MP, Duffy DC (1988) Contemporary and historical patterns of African Penguin Spheniscus demersus distribution at sea. Estuar Coast Shelf Sci 26:447-458

Wilson RP, Spairani HJ, Coria NR, Culik BM, Adelung D (1990) Packages for attachment to seabirds: What color do Adelie penguins dislike least? J Wildl Manag 54(3): $447-451$

Wilson RP, Culik BM, Adelung D, Spairani HJ, Coria NR (1991) Depth utilisation by breeding Adelie penguins Pygoscelis adeliae at Esperanza Bay, Antartica. Mar Biol 109:181-189

Wilson RP, Scolaro JA, Peters G, Laurenti S, Kierspel M, Gallelli H, Upton J (1995) Foraging areas of Magellanic penguins Spheniscus magellanicus breeding at San Lorenzo, Argentina, during the incubation period. Mar Ecol Prog Ser 129:1-6

Wilson RP, Kreye JM, Lucke K, Urquart H (2004) Antennae on transmitters on penguins: balancing energy budgets on the high wire. J Exp Biol 207:2649-2662 